\title{
Vicente Artuso*
}

\section{Relações de dominação e violência em Números 12,1-12 E 16,1-35: Abordagem na perspectiva dos fracos, dos vencidos}

\author{
Relaciones de dominación y violencia en Numeros 12,1- \\ 12 Y 16,1-35: Abordaje a partir de \\ los débiles, de los vencidos
}

\section{Relationships of domination and violence in Numbers 12,1-12 and 16,1-35: Approach from the weak, from the vanquished}

\begin{abstract}
Resumo: 0 estudo comenta os textos de Num 12,1-12 e 16, 1-35 através da ótica dos fracos e oprimidos. Se difere de autores que vêem como incontestável a autoridade dos líderes. Estes textos enaltecem o poder de Moisés e Aarão no fato de que o castigo é implacável contra os rebeldes. São situações de crise, onde as relações são marcadas por atitudes autoritárias, e o poder é legitimado pela teologia oficial da elite sacerdotal. Percebe-se que a base não é ouvida, o que contrasta com a teologia do Êxodo e da Aliança. Neste contexto se entende a enorme desproporção entre a culpa e castigo. Isso gera uma forte suspeita de uma ideologia excludente da classe popular, das mulheres, dos pobres que não são ouvidos. A narrativa do conflito de Miriam e Aarão contra Moisés é construída para legitimar a autoridade de Moisés, enquanto a narrativa da revolta de Core Datã e Abiram serve para legitimar a autoridade de Aarão. Isto reflete o conflito de autoridade no pós-exílio, com uma teologia que revela a imagem de Deus ao lado dos líderes e não atento aos clamores dos pobres.
\end{abstract}

Palavras-chave: Moisés, liderança, dominação, conflito.

* Profesor de maestría y doctorado en Teología de la PUCPR Curitiba-PR. 
Resumen: El estudio comenta los textos de Num 12,1-12 y 16,1-35 desde la óptica de los débiles y oprimidos. Se diferencia de autores que ven la autoridad de los líderes como incontestable. Estos textos exaltan el poder de Moisés y de Aarón en el hecho de que el castigo es implacable contra los rebeldes. Son situaciones de crisis, donde las relaciones están marcadas por actitudes autoritarias, y el poder es legitimado por la teología oficial de la élite sacerdotal. Se percibe que la base no es escuchada, lo que contrasta con la teología del éxodo y de la alianza. En ese contexto se entiende la desproporción enorme entre la culpa y el castigo. Eso levanta una fuerte sospecha de una ideología excluyente de la clase popular, de las mujeres, de los pobres que no son escuchados. La narración del conflicto de Miriam y Aarón contra Moisés es construida para legitimar la autoridad de Moisés, mientras que la narración de la revuelta de Coré Datán y Abiram sirve para legitimar la autoridad de Aarón. Esto refleja el conflicto de autoridad en el post-exilio, con una teología que revela la imagen de Dios al lado de los líderes, y no atento al clamor de los pobres.

Palabras-clave: Moisés, liderazgo, dominación, conflicto.

Abstract: The study comments on the texts of Num 12,1-12 and 16,1-35 from the perspective of the weak and oppressed. It differs from authors who see the authority of leaders as incontestable. These texts exalt the power of Moses and Aaron in the fact that the punishment is implacable against the rebels. They are situations of crisis, where relations are marked by authoritarian attitudes, and power is legitimized by the official theology of the priestly elite. It is perceived that the base is not heard, which contrasts with the theology of the exodus and the alliance. In this context we understand the enormous disproportion between guilt and punishment. That raises a strong suspicion of an exclusive ideology of the popular class, of women, of the poor who are not listened to. The narration of the conflict between Miriam and Aaron against Moses is constructed to legitimize the authority of Moses, while the narration of the revolt of Korah Dathan and Abiran serves to legitimize the authority of Aaron. This reflects the conflict of authority in the post-exile, with a theology that reveals the image of God beside the leaders, and not attentive to the cry of the poor.

Keywords: Moses, leadership, domination, conflict.

\section{Introdução}

0 vocabulário em torno da corrupção é bem evidente nas denúncias proféticas: denuncia dos que torcem ('akesh) o que é reto e detestam o direito (Mq 3,9), do que esmaga no pó a cabeça dos fracos e torna torto (yatheh) o caminho dos pobres (Am 2,7), o que absolve o ímpio mediante presente (suborno) (Is 5,23). A Corrupção nasce da ganância seguida da exploração dos fracos.

O campo semântico em torno do pecado e corrupção se amplia com outros termos: (pesha) delito, crime; hatta't, pecado ('awel), depravação, falsidade ('awon) perversão, delito. Esse vocabulário não é comum em textos narrativos do pentateuco, e muito raro no livro dos Números. 
Porém há narrativas que espelham uma situação de injustiça, se lidas na ótica do pobre e do oprimido, á luz da teologia do êxodo e da aliança.

O presente estudo se ocupa de alguns textos do livro dos Números nos quais o uso do poder para dominar parece prática normal. São textos escritos na ótica dos vencedores que detêm o poder. Nesse sentido os leitores que se identificam com os vencidos irão questionar: "Deus está conosco ou está contra nós"? (cf. Westermann Dicionário Teológico Manual del Antiguo Testamento; Pecado, culpa in: Alexander e D.Baker. Diccionario del Antiguo Testamento. Pentateuco, p.609ss).

A ótica de leitura a partir dos fracos e oprimidos permite constatar os contrastes com a teologia da aliança baseada na solidariedade e misericórdia. Os relatos espelham uma cultura com leis e costumes que agridem a integridade e dignidade humanas. Nos textos de conflito de lideranças as relações são por vezes marcadas por atitudes autoritárias quando não legitimadas pela teologia oficial da elite sacerdotal no poder. Assim a corrosão das relações entre lideranças e povo é marcada pelas injustiças que penalizam os fracos que não tem voz.

O livro dos Números teve uma composição complexa, reunindo diferentes tradições, algumas bem antigas, pré-exílicas, outras em grande parte oriundas da tradição sacerdotal do final do período persa e até do início do período grego (cf. Enzo Appella, 2013, p.234) Não é nossa intensão discutir a composição do livro, tomamos o texto como produto histórico-social no período pós-exílico quando os sacerdotes, chamados "aronitas" se estabeleceram no poder. Na verdade grupos vindos do exílio tentaram ocupar a liderança sobre o povo, não raro à custa de violência e com apoio da teologia por eles produzida. Do ponto de vista teológico essa imagem de Deus que houve os poderosos e ignora o clamor do povo, é contrastante com o Deus do Êxodo que escuta o clamor do pobre e desce para libertar. Há um distanciamento do ideal de uma sociedade igualitária, sem violência e dominação. Os textos a ser analisados apresentam indícios claros da ideologia do grupo aronita que usurpando o direito dos levitas se apossaram da liderança. Esse contexto indica o distanciamento da religião que agrada a Deus. 0 que Deus pede é "o amor da misericórdia" (Mq 6,6) "cessar de praticar o mal, fazer o bem, buscar o direito, fazer justiça ao órfão, defender a viúva", (Is 1,16-17).

A ótica profética a partir dos vencidos não é considerada por comentadores dos textos. Em Nm 16-17, segundo De Vaux (1972, p.189) se encontra uma completa teologia do sacerdócio: a sua origem divina, 
o seu caráter sacro, o seu papel litúrgico, mas acima de tudo a sua função expiatória, pois as teologias do pecado e do sacerdócio estão intimamente ligadas". 0 autor não suspeita da ideologia que estaria por trás do conteúdo violento dos relatos e não se pergunta por que a ira do Senhor pode levar ao extermínio os revoltosos. Igualmente Enzo Appella (p.14), seguindo A. Schart (1990, p. 223) explica que a reação de Deus com o castigo, é simplesmente sinal que as murmurações são graves e ofensivas a ponto de provocar a mais drástica punição de todo o Êxodo. "Se Deus agiu dessa forma é porque está diante de uma rebelião mais ofensiva de todas, mais que aquela do bezerro de ouro (Ex 32) e ainda mais do que aquela que colocou ao descrédito a terra de Canaã após a prova de sua abundância (Nm 13)" (RIVKIN, 1988, 580 apud APPELLA, p.14). Nenhum desses autores ousa questionar porque o castigo é tão desproporcional, uma vez que não se afastam da interpretação tradicional de que essas narrativas foram escritas para trazer uma teologia do sacerdócio, cujo poder é incontestável. Assim Timothy Ashley (295) "O ponto central desses capítulos é a relação do sacerdócio aronita com o resto dos levitas. Este é o problema subjacente na revolta de Coré em Nm 16. Essas histórias assumem material já conhecido do Pentateuco (Ex 28-29; Lv 8-10) para tornar clara a escolha divina de Aarão e sua família para o sacerdócio". Mais adiante o autor qualifica os motivos da revolta apenas por ambição de poder dos revoltosos e não questiona os líderes! Outro autor, Gordon J. Wenham, qualifica Coré como um protótipo de herege, porque esse levita afirma a santidade da congregação, negando a santidade dos líderes (pg. 141). Wenham sequer pergunta sobre a legitimidade da reclamação com base em Nm 15,40. A nossa interpretação é de que Coré não coloca em questão a santidade de Moisés e Aarão, mas o exercício da autoridade no fato de se colocar acima da assembleia (Nm 16,3). Pretendemos mostrar que a base teológica de que toda a congregação é santa (Nm 16,3) não deixa de ser legítima e propõe uma organização mais participativa. Leigos e sacerdotes são povo santo de Deus antes de tudo.

\section{A fala de Mirian e Aarão contra Moisés (Nm 12,1-16)}

A redação final de Números foi realizada depois do exílio da Babilônia. Encontra-se nele vários elementos que mostram situações de conflitos. Em Nm 12,1 temos a fala de Mirian e Aarão contra Moisés porque ele havia tomado uma mulher cuchita, uma estrangeira. Alguns 
têm interpretado a fala de Aarão e Mirian como uma reprovação racista contra Moisés por ter se unido a mulher estrangeira. Nesse caso ela se situa no contexto do projeto da raça pura do período das reformas de Esdras e Neemias. 0 povo de Israel, raça escolhida e nação santa, não deve se misturar com os estrangeiros. "As proibições de mistura e casamentos com estrangeiros agiam como recordações diárias de que Deus havia separado Israel das nações para ser um povo de sua propriedade exclusiva (WENHAN, 1985, p. 34). Nesse caso Aarão e Mirian com sua fala contra Moisés representariam o grupo em defesa da raça pura do período de Esdras e Neemias. Porém segundo Mary Douglas (1993, p. 264) apenas essas falas não explicam a severidade da punição desproporcional ao castigo recebido por Mirian. 0 castigo está antes ligado à contestação da autoridade única de Moisés. É o que veremos. Outra característica da época pós-exílica é a afirmação da religião extremamente ligada ao templo e a figura do sacerdote indispensável para preservar a saúde espiritual da nação. Buscava-se restaurar aquilo que foi perdido no exílio, isto é o ideal de "caminhar juntos com o Senhor como povo sacerdotal, nação santa". Os relatos especialmente na segunda parte de Números "servem para que situações vividas no segundo templo recebam raízes antigas e legitimadoras" (GALLAZZI, 1996). Essa era uma prática constante: quando se queria legitimar algo, se buscava afirmar como verdadeiro o que já era praticado desde a antiguidade. Assim certas práticas são justificadas como projeto a ser realizado em vista da raça pura e um governo sacerdotal centralizado. A ideologia do poder centralizado pode ser identificada em alguns textos escritos na ótica dos vencedores sem atender às reclamações do povo humilde.

\subsection{A liderança de Mirian}

Miriam é mencionada em uma genealogia, e junto com os irmãos Moisés e Aarão: "O nome da mulher de Amram era Jocabed, filha de Levi, que nasceu no Egito. Ela deu a Amram os filhos Aarão, Moisés e Miriam, a irmã deles" (Nm 26,59). 0 que tudo indica ela aparece, mas não é mencionado seu nome em Ex 2,1-10 sendo apresentada como irmã mais velha de Moisés (Ex 2,4.7). Nesse relato ela vê o cesto com o menino Moisés e, no momento que a filha do Faraó ao ver o menino sentiu compaixão (Ex 2,6), usou a esperteza para mediar a salvação. Falou com a filha do Faraó que imediatamente autorizou procurar uma mulher para criar e educar Moisés. Após a travessia do mar em Ex 15,20-21, ela é chamada de profetisa Mirian, irmã de Aarão. Nessa 
ocasião ela exerceu sua liderança ao cantar um hino de vitória, seguida por todas as mulheres que celebravam a libertação entre toques de tamborins e dança. Ela convida o povo a cantar: "cantai ao Senhor, porque atuou com grandeza: cavalo e cavaleiro lançou no mar" (Ex 15,20-21). Também o profeta Miquéias inclui a participação de Miriam como líder, quando apresenta o Senhor com as seguintes palavras: "Eu te fiz subir da terra do Egito, da casa dos escravos te libertei. Enviei a tua frente Moisés, Aarão e Miriam" (Mq 6,4) (Grenzer, 2004, p.135-136). Portanto Miriam aparece em momentos chaves da história da libertação do povo: No início agiu para salvar a vida de Moisés (Ex 2,1-10) depois da travessia do mar liderou a celebração da libertação (Ex 15,21-22) e também no deserto foi ousada a criticar a autoridade de Moisés. Todas essas informações conferem grande autoridade à tradição de Mirian (cf. LUISE SCHOTTROFF; SILVIA SCHROER; MARIE-THERES WACKER, 2008, p.67).

\section{2. $O$ conflito com Moisés e castigo}

Detemos-nos em um texto chave (Nm 12,1-12), em que Mirian é personagem de destaque. Nesse texto é citada sete vezes ( Nm 12,1.4.5.10.15). Ela e o irmão Aarão falam a Moisés: “... falou o Senhor somente por meio de Moisés? Não falou também por meio de nós?". O narrador acrescenta: "e o Senhor ouviu" $(12,2)$. Faz-se então um intervalo narrativo, o questionamento fica no ar, pois Moisés não responde. Então o narrador toma a palavra. "O homem Moisés era muito humilde, mais que todo o ser humano que está sobre a superfície do solo" (Nm 12,3). Esta informação sobre Moisés, após as queixas de Miriam e Aarão prepara e até antecipa o discurso positivo do Senhor em favor de Moisés.

O Senhor faz uma convocação dos três: Moisés, Aarão e Miriam na tenda do encontro (Nm 12,4). Porém a Palavra do Senhor em defesa de Moisés é dirigida somente a Aarão e Miriam: "Se houver um profeta dentre vós, eu o Senhor, em uma visão a ele me darei a conhecer. Em sonho a ele falarei. Não é assim, com meu servo Moisés. Em toda minha casa ele é fiel. Boca a boca, falo com ele e em visão, não em enigmas. Ele contempla a figura do Senhor. Então, porque não temeis de falar contra o meu servo, contra Moisés?" (Nm 12,6-8). E o narrador acrescenta: "E se acendeu a ira do Senhor contra eles" (Aarão e Miriam). 0 texto claramente destaca as qualidades e privilégios de Moisés: muito humilde, mais que todos $(12,3)$, ele é fiel $(12,7)$, é profeta com quem 
o Senhor fala boca a boca, fala em visão, não em enigmas, contempla a figura do Senhor $(12,8)$. A apologia é aumentada e o motivo parece ser a queixa dos dois por causa da liderança única de Moisés. A apologia revela que a liderança de Moisés era protegida ciosamente. Parece não haver motivo à primeira vista, sendo que os três estão no mesmo nível e comparecem diante da tenda onde o Senhor se comunica. De qualquer forma o discurso de Deus sinaliza um conflito de autoridade de Moisés como líder. Seu poder parece inquestionável, dada a extensão do discurso do Senhor em favor de Moisés, e a ira do Senhor como reação ao questionamento de Miriam e Aarão. Outro fato é destacado como reação à fala de Mirian e Aarão: "A nuvem se desviou de cima da tenda". Porém somente Miriam ficou desprotegida, pois "tornou-se leprosa, branca como a neve" (Nm 12,10). Aqui observa-se uma diferença abissal entre uma possível ofensa a Moisés e o castigo sobre Miriam. Se os três tinham participação da tenda, como profetas, dois reclamaram com Moisés, e um, fora punido de forma tão desproporcional? Porque o autor relata o castigo apenas sobre Miriam? 0 texto sinaliza exclusão e preconceito contra os mais fracos e a exaltação da autoridade de Moisés. Fato semelhante ocorreu na montanha do Senhor, quando o povo foi punido duramente e morreram muitos, por causa da adoração do bezerro de ouro, enquanto Aarão que havia liderado a campanha da fabricação do bezerro, não foi castigado e sequer foi reprendido (Ex 32). Como também em Nm 12, nada se diz dos efeitos da ira do Senhor sobre Aarão. Não bastasse a lepra de Miriam, ela foi excluída do acampamento por sete dias conforme a lei (Nm 5,1-3). Além do mais segundo R.G. Branch, o Senhor confirmou a justiça do castigo de Miriam e o comparou com a impureza de uma cusparada de um pai no rosto de sua filha! Vemos como num crescendo a narrativa exalta Moisés o mais humilde e humilha expõe à vergonha a irmã, líder e profetiza Miriam. Ela morreu em Cades e ali foi sepultada (Nm 20,1). 0 texto não menciona o pranto e luto de trinta dias como ocorreu na morte de Aarão (Nm 20,29) e Moisés (Dt 34,8).

\section{A revolta e castigo do grupo de Coré (Nm 16,1-35)}

Outro relato em favor da autoridade de Moisés e Aarão é a história da revolta de Coré, Datã e Abiram em Nm 16, 1-35. Ele é situado no contexto da parada em Cades ocasião de muitos conflitos e murmurações contra os líderes. Desta vez é Moisés que defende a autoridade 
de Aarão diante dos revoltosos: "Quem é Aarão para que murmureis contra ele"? (Nm 16,11b). 0 texto é escrito na ótica dos vencedores, e espelha uma imagem de Deus que dialoga com Moisés, mas não ouve as reclamações do povo. A história mostra que o amotinar-se contra a autoridade é revoltar-se contra Deus (Nm 16,11a). Como consequência todos os revoltosos foram aniquilados pela ira divina sem poder de defesa. Também aqui é infligido um castigo desproporcional com o suposto pecado da revolta contra a autoridade de Moisés e Aarão. Essa cena contrasta com o relato do Êxodo (Ex 1-15) no qual Deus escuta o clamor do povo, desce para libertar. Veremos a legitimidade dessas reclamações e o cunho ideológico do texto escrito na ótica dos vencedores. A revolta não é contra Deus, mas contra Moisés e Aarão. No entanto o texto apresenta a imagem de Deus irado por causa da revolta contra a liderança principal. São textos que revelam intolerância com qualquer oposição a autoridade como se observou em Nm 12,1-12. Isso sinaliza uma corrosão das relações do povo com os líderes, com acusações de ambas as partes. Os líderes se colocam acima da assembleia do povo (Nm 16,3) e não escutam suas críticas e clamores por causa do poder. Esta história contrasta com Nm 11,24-30, que espelha o ideal de uma comunidade profética e participativa: "oxalá todo o povo fosse profeta"! Ou ainda Ex 18,1-37, a bela história de diálogo e escuta de Moisés receptivo dos conselhos de Jetro seu sogro.

\subsection{Autoridade dos líderes}

Nossa abordagem será na ótica dos oprimidos por isso tratamos dos personagens que se revoltaram contra Moisés e Aarão e foram castigados. 0 texto relata que Coré, Datã, e Abiram com cento e cinquenta homens de nome, chefes do povo, se levantaram contra Moisés e Aarão. Quais os motivos dessa revolta? Qual o motivo dessa terrível história de castigo?

\subsection{Coré}

0 autor descreve sua origem como descendente de Levi, da mesma forma como Moisés e Aarão, em Ex 6,16-26, são descendentes de Levi. Conforme Ex 6,21-24, Coré é descendente de Levi e primo de Moisés e Aarão. A tradição de Coré como levita é bem documentada (cf. Ex 6,21-24; 1 Cr 6,7; 6,23). Coré é apresentado como filho de Isaar, filho de Cata, filho de Levi (cf. Ex 6,16-21). Cata, filho de Levi (cf. Gn 46,11; Ex 6,16; Nm 3,17; 1Cr.5,17), deu origem ao clã caatita (Nm 3,27), uma 
divisão de levitas encarregados do serviço do santuário ( $\mathrm{Nm} \mathrm{3,28).}$ Coré fazia parte da família de Isaar, um dos filhos de Caat (Nm 3,19; Ex 6,18). Todos esses grupos de levitas acampavam no lado Sul da habitação (Nm 3,29) (BROWN; DRIVER; BRIGGS, 1951, 875.895-896).

O parentesco levítico de Coré, em Nm 16,1a, e também o parentesco levítico de Moisés e Aarão (cf. Ex 6,16-21) preanunciam conflitos entre levitas de grupos diferentes. Dentre o grupo dos levitas, os caatitas, na pessoa de Coré, contestaram o sacerdócio dos aronitas. 0 pai de Coré, Isaar, era irmão do pai de Moisés e Aarão: Amram (Ex 6,18.20; $\mathrm{Nm} \mathrm{3,19).} \mathrm{A} \mathrm{esta} \mathrm{luta} \mathrm{entre} \mathrm{primos} \mathrm{se} \mathrm{poderia} \mathrm{acrescentar} \mathrm{o} \mathrm{fato} \mathrm{de}$ que Moisés havia colocado como chefe dos caatitas, Elisafan ( $\mathrm{Nm} \mathrm{3,30),}$ filho de Oziel, última família de Caat (Nm 3,27), o grupo com menos direitos (BOSCHI, 1976, p. 141). Isto também deve ter dado motivo para a revolta e uma disputa mais acirrada por melhores posições ou encargos na hierarquia. Esse é o contexto dos discursos de Moisés dirigidos a Coré e à sua congregação (v.5a.8a), composta também dos filhos de Levi (v.7e.8a-b.10a) (cf. ARTUSO, 2008, p. 60-61).

\subsection{Datã e Abiram}

Na tradição bíblica, os nomes Datã e Abiram são citados sempre juntos (cf. Dt 11,6; Nm 26,9; Sl 106,17). Conforme mostram os textos, eles são rubenitas, pois Eliab e Felet ("Falu") eram filhos de Ruben (Nm 26,5.8). Historicamente, podem ter se sentido desprezados. A tribo de Ruben havia perdido o direito de primogenitura (cf. Gn 49,2-4; Gn 29,32), e certamente aspirava uma função maior na nação (ASHLEY, 1993, p. 303). Conforme o livro dos Números (Nm 2,10; 3,29), os dois grupos acampavam um ao lado do outro no lado Sul da habitação, e também marchavam um na frente do outro. "Pela proximidade se explica o envolvimento mútuo e seu destino comum" (WENHAN, 1985, p. 141). Tinham eles ampla oportunidade de condoer-se de suas perdas mútuas de poder e influência. Esse passado histórico de classes relegadas, e também a proximidade geográfica, propiciou a união entre eles para formar a revolta.

\subsection{Outros grupos}

Vemos, nas falas diretas de Moisés, como o autor introduz outros grupos em conflito de autoridade, que não aparecem no v.1-3a. 0 grupo de Coré vai além dos duzentos e cinquenta líderes leigos. Compõe-se também de levitas. Além do grupo de Coré, na mesma época, outros 
grupos haviam se rebelado ${ }^{1}$. 0 texto apresenta a procedência e o status social dos duzentos e cinquenta que se somaram a Coré e seus companheiros. No v. 2a, são homens dentre os filhos de Israel, são membros das tribos leigas de Israel, em oposição aos levitas (cf. Nm 1,2.47). Os duzentos e cinquenta são homens "dentre os filhos de Israel". No v. $2 \mathrm{~b}$, é dito que são "homens de nome"; portanto, eram conhecidos e de boa fama. Estes eram os chefes de família conhecidos por suas proezas também como guerreiros. No mesmo versículo, são conhecidos como "chefes da congregação". Em Nm 4,34; 31,13; 32,2, são mencionados sempre muito próximos de Moisés ou Eleazar para realizar certos trabalhos importantes (cf. ARTUSO, 2008, p. 63-64).

\subsection{A revolta}

Em Nm 16,1-3 a revolta se inicia envolvendo todos os líderes: Coré, Datã, Abiram, On e os duzentos e cinquenta notáveis que "reuniram-se contra..." (Nm 16,3a). No decorrer do texto, irão aparecer outros personagens que também tinham papel importante. Do lado de Moisés, os anciãos (Nm 16,25), do lado dos que se revoltaram, se associam também os levitas (Nm 16,7.-7.10). A Deus caberá decidir em favor de quem vai acontecer o desfecho da história. Portanto esta revolta se trata de uma ação, que não depende de um, mas de um grupo que se reúne. Em Nm 16,3 o verbo reunir-se é seguido da preposição adversativa ("contra"), Em outras partes do Pentateuco, este verbo encontra-se em contexto de forte revolta contra a liderança de Moisés e Aarão (Nm 20,1) ou contra Aarão apenas (Ex 32,1). Todos juntos disseram a Moisés e Aarão $(16,3)$ : "Basta, se toda a congregação é santa porque vos elevais acima da assembleia do Senhor"? A expressão "basta" (hebraico "rab lachen") usada elipticamente, pode-se traduzir: "vocês foram longe demais"2. Em Ez 45,9 e Dt 1,6; 3,26, na boca de Deus, expressa também indignação pelo que aconteceu. Teria sido, nos tempos primitivos, o slogan preferido dos rebeldes para rejeitar os privilégios de Moisés e

Conforme Nm 27,3, Salfaad, um manassita, não pertenceu ao grupo de Coré, mas morreu no deserto por causa do seu pecado. Isso indica que outros grupos se rebelaram. Estes não eram do grupo de Coré, mas morreram também por causa do seu pecado.

2 Hebraico "rab-lakem", "é muito para vós", "é demais". É uma expressão de desabafo. Tradução da Revised Standard Version ("You have gone too far"). Outras traduções: "o suficiente para vossas pretensões" "basta” (cf. GRAY, B. G. A Critical and Exegetical Commentary on Numbers, p. 197), "vocês se excederam" (BUDD, P. J. Numbers. p. 186; NOTH, M. Numbers, p. 123). 
Aarão $0^{3}$. 0 motivo da queixa não parece ser ambição dos revoltosos, ou ciúme, apenas. Moisés e Aarão são acusados de se colocarem "acima da assembleia", o que é suspeita de poder de dominação. O grupo dos revoltosos se organiza contra e tem coragem de falar. Estão no limite e desabafam "Basta". O narrador mostra que o grupo fez valer seus direitos de povo libertado. "Em vez de resignação e silêncio, aproveita a liberdade que o Êxodo lhes forneceu" (GRENZER, 2000, p.123), para manifestar em comunidade seus problemas e exigir dos seus líderes uma solução. São reclamações legítimas e fundadas no princípio que toda a congregação é santa, "reino de sacerdotes e nação consagrada" (Ex 19,6). A santidade não significa apenas um status de povo separado, mas o status de ser "povo de Deus", são os que observam os mandamentos e guardam a aliança (Ex 19,5; Nm 15,40). Um povo sacerdotal é um povo com uma organização mais democrática, participativa. Quando também levitas se juntaram a revolta a reação de Moisés é defender o irmão: "E Aarão que é ele, para que murmureis contra ele?" (v. 11b). Porém quando Datã e Abiram são convocados por causa da revolta e se recusam, o texto narra que "Moisés ficou muito irado" (Nm 16,5). A glória de Deus, em 16,19b, apareceu no momento decisivo do enredo, como sinal de sua presença julgadora. Era uma necessidade, pois Moisés já havia invocado YHWH contra os revoltosos: "Não voltes para a oferta deles” (16,15c)! (cf. ARTUSO, 2008, pg. 54.66-70).

\subsection{Castigo: "A ira de Deus aniquilou os revoltosos"}

Moisés propõe uma ação ao grupo de Coré: fazer uma oferenda de incenso no dia seguinte (v. 6-7). Trata-se de um ordálio, uma espécie de teste. A prova consiste na apresentação de uma oferta restrita aos sacerdotes, por pessoas não autorizadas, para mostrar quem é santo. Conforme Martin Noth, trata-se de um julgamento divino ao qual eles devem submeter-se. YHWH, pelo modo que recebe esta oferenda, tornará conhecida sua escolha e decidirá a questão da santidade (Numbers, 1966, p. 124). Como a revolta contra Moisés e Aarão foi considerada uma revolta contra Deus (v. 11a), o ordálio torna-se uma prova judiciária com objetivo de determinar a culpabilidade dos acusados, ao submetê-los a um risco: a sanção terrível vinda do próprio Deus.

0 enredo mostra que o julgamento de Deus será em favor de um

Para DE VAULX (1972, p.191), esses acontecimentos seriam da época da organização do culto, ou aquela da reação anti-levítica de Jeroboão (cf. 1Rs 12,31). Para outros, é a época a partir do segundo templo que reflete o conflito entre levitas e aronitas (Gray, Wenham, Budd). 
grupo sagrado cuja posição é intangível. Nesse sentido, a proposta ao grupo de Coré, de um oferecimento de incenso, pode ser interpretada também como reductio ad absurdum do clamor pela santidade de todos no v. 3 (NOTH, 1966, p.124). É tão certo quem "será o homem que o Senhor escolher, o santo será ele” (v. 7c-d), Aarão. Assim é certo que um oferecimento de incenso, por pessoas não credenciadas, acarreta o castigo inevitável do Deus (cf. Lv 10,1-2). Após o castigo ninguém sobreviverá dos duzentos e cinquenta líderes. "Um fogo da parte do Senhor saiu e consumiu os duzentos e cinquenta homens que ofereciam incenso" (Nm 16,35), restando Moisés e Aarão na entrada da tenda. Somente Aarão será credenciado para o oferecimento do incenso. Será ele a estancar a praga da doença que caiu sobre o povo no dia seguinte por causa de outra revolta contra Moisés e Aarão (Nm 17,6-15).

Quanto ao grupo de Datã e Abiram tão logo os filhos de Israel se separaram deles, a terra abriu sua boca a seus pés e foram engolidos juntamente com suas famílias e tudo o que possuíam ( $\mathrm{Nm} \mathrm{16,30-33).}$ Ocorreu uma descida ao sheol de forma incomum, ainda com vida o grupo foi engolido pela terra. Foi de fato uma forma particularmente terrível do castigo. Primeiro são citados os culpados e as casas deles (v. 32b), quem são os familiares, e depois todos os seus pertences. Pelo fato do castigo vir por culpa de Coré, Datã e Abiram, seus familiares e pertences também tornaram-se objeto de castigo. A descida ao sheol é a descida ao sepulcro, pois a terra cobriu-os e pereceram desaparecendo do meio da assembleia. Nenhum vestígio restou da ruína, nem de seus pertences, nem do lugar onde estavam ${ }^{4}$. A terra cobriu sobre eles, como a tampa do sepulcro (cf. Is 26,21). A forma do julgamento como descida ao sheol marca então a separação definitiva da congrega-

\footnotetext{
A retribuição como castigo coletivo da conduta do indivíduo era um dado comum no Antigo Testamento. Assim, por causa do rapto de Sara, também a casa dos culpados é castigada (Gn 12,17; 20,7); é o caso de: Coré e seu grupo (Nm 16,20-30), Eli (1Sm 2,31), Davi (2Sm 12,10), Jeroboão ( 1 Rs 14,10). Com a monarquia, a retribuição coletiva, aos poucos, perdeu sua razão de ser, pois acabou a independência própria dos clãs, tribos e famílias. Assim, em 2Rs 14,6 e na lei de Dt 24,16 , proíbe-se a aplicação da retribuição coletiva. A mentalidade do povo muito lentamente foi mudando. Nos salmos (Sl 34,28.38; 109,9-14) e na literatura sapiencial (Sb 3,12; 4,3-6; Eclo 41,5-7), encontram-se ainda resquícios do espírito antigo (cf. NELIS, Retribuição. In: VAN DEN BORN, A. (Org.). Dicionário Enciclopédico da Bíblia, col. 1317). Essa retribuição a Datã e Abiram parecia exagerada aos próprios rabinos. No Talmud, temos um trecho em que "Ana reza por eles". Assim como Aarão intercedeu por Mirian. Esta é a opinião de Rabbi Iehoshua Ben Levi. Então rabi disse em nome do rabi Jossi: "Assim afundou a tribo de Coré para baixo até que Ana apareceu, rezou por eles e disse: O Senhor mata e faz viver. Leva para o sheol e eleva novamente (cf. 1 Sm 2,6; J. Sanherin 10,1) (Os textos são citados in: STAUBLI, T. Levitikus, Numeri, p. 267).
} 
ção. Os três verbos juntos (descer, cobrir, desaparecer) colocam ênfase na destruição definitiva sem possibilidade de retorno. Assim como o fogo da parte do Senhor queimou totalmente os duzentos e cinquenta líderes, que ousaram oferecer um incenso irregular.

\section{Conclusão}

As murmurações fortes do povo são frequentes na caminhada no deserto, antes do Sinai (Ex 15,22-25; 16,1-36; 17,1-7) e depois do Sinai (Nm 11,2; 12,2; 14,2; 15,24; 16,2. 17, 6-7; 21,4-9) (cf. SCHART, 1990, p. 47-49). Em nossos textos mais que falas (Nm 12,1-2) ou murmurações, aparecem também revoltas contra a autoridade de Moisés e Aarão (Nm 16,3.13-14). Algumas particularidades sinalizam que os textos foram escritos para legitimar os líderes no poder, a qualquer custo. A narrativa do conflito de Miriam e Aarão contra Moisés é construída para legitimar a autoridade de Moisés. Assim a repreensão dura do Senhor em Miriam, além da humilhação e lepra, revela o quanto são criminalizadas as pessoas que se levantam contra as autoridades constituídas. Nesse caso, o texto não se refere à revolta, mas apenas à fala dos dois irmãos ao criticar Moisés. Essa desproporção entre o que se poderia chamar de pecado, com o castigo que segue choca nossa cultura. Revela uma sociedade onde a violência era tolerada em nome da justiça para reprimir revoltas. Pensava-se que eliminado o pecador eliminava-se o mal. Na perspectiva profética Deus não quer a morte do pecador e sim que viva. (Ez 18,23). Na narrativa da revolta de Coré, Datã e Abiram com os duzentos e cinquenta líderes, a desproporção entre pecado-transgressão é mais abissal. Todos os revoltosos foram castigados e aniquilados sem trégua. Esses corajosos grupos se levantaram contra Moisés e Aarão e disseram: Basta! Se toda a congregação é santa, porque vos elevais acima da assembleia do Senhor? (Nm 16,1-3). Essa revolta se espalhou em meio à comunidade toda que após o castigo do grupo de Coré, Datã e Abiram, no dia seguinte murmurou contra Moisés e Aarão: vocês fizeram "morrer o povo do Senhor" (Nm 17,6). 0 resultado dessa queixa foi uma praga que aniquilou 14.700 pessoas do povo $(\mathrm{Nm}$ 17,14). Então o rito do incenso de Aarão fez cessar a praga. Assim esse texto visa legitimar a autoridade de Aarão, e seu monopólio sobre o culto.

A abordagem desses textos na ótica de gênero denuncia relações de opressão, violência. Trata-se de uma visão mais crítica a partir dos 
oprimidos, para dar visibilidade, às classes sofredoras do povo, às mulheres (Mirian) aos fracos e não aos vencedores. Nosso estudo revela que esses textos são escritos na ótica dos vencedores, projetando a culpa para os fracos. Assim "Datã e Abiram" são considerados "homens ímpios" (Nm 16,26). Também as murmurações dos levitas liderados por Coré contra Aarão foram consideradas ofensas contra Deus (Nm 16,11). Portanto é importante perceber o lado ideológico dos textos. Nosso estudo denunciou estruturas de poder e discurso que legitima a inferioridade das classes oprimidas como é Nm 12 e 16. É patente que alguns textos espelham uma situação de opressão visível que alguns estudiosos não suspeitam, até mesmo diante das evidências. Tentam fazer teologia em narrativas cujo conteúdo contrasta com a revelação de Deus no êxodo. Damos um exemplo "Nesses capítulos se encontra uma completa teologia do sacerdócio: a sua origem divina, o seu caráter sacro, o seu papel litúrgico, mas acima de tudo a sua função expiatória" (De Vaux, 1972). 0 autor omite de criticar a moldura do texto, mesmo que possua elementos da teologia do sacerdócio. 0 Deus do êxodo está do lado dos fracos, daqueles abaixo das condições mínimas de vida, dos vencidos. A ânsia de poder conduz a uma situação de injustiça: que penaliza os fracos em favor dos fortes. Juvenal bem expressava. "Censura dat veniam corvis sed vexat columbas" (A censura dá o perdão aos corvos mas castiga as pombas). Portanto, numa sociedade de ricos e poderosos, quando estes são sujeitos de juízo, é mais provável que os pobres e fracos sejam punidos, enquanto os culpados distorcem a lei a seu favor e acabam inocentados.

\section{Referências}

APPELLA, Enzo. Autorità contestata e confermata. Ambizione umana e progetto divino nella storia di Core, Datan e Abiram ( $\mathrm{Nm}$ 16).Gruppo editoriale Il Pozzo di Giacobbe, 2013.

ARTUS, O. Etudes sur le livre des Nombres : récit, histoire et Loi en Nb 13,120,13. Fribourg: Universitaires, Göttingen: Vandenhoeck \& Ruprecht, 1997.

ARTUSO, Vicente. A revolta de Coré, Datã e Abiram. Análise Estilístico-Narrativa e interpretação. São Paulo: Paulinas, 2008

ASHLEY, T. The book of Numbers. Michigan: Eerdmans Publishing, 1993.

DE VAUX, J. Les Nombres. Paris: J. Gabalda Editeurs, 1972. 
BOSCI, B. G. Numeri. Roma: Paoline, 1976. 260p. (Nuovissima versione della Bibbia, 4).

BROWN, F.; DRIVER, S. R.; BRIGGS, C. A. A Hebrew and English Lexicon of the Old Testament. 6. ed. Based on the Lexicon of William Gesenius. Oxford: Clarendon Press, 1951.

BUDD, P. J. Numbers. Waco \& Texas: General Editors, Word Books, 1984. 409p. (Word Biblical Commentary, 5)

DOUGLAS, M. Nel Deserto: La dottrina della contaminazione nel libro dei Numeri.Traduzione Alfredo Damanti. Bologna: Edizioni Dehoniane, 2001.

GALLAZZI, A. A Teocracia Sadocita: sua história e ideologia. Macapá: Biblioteca de Estudos Bíblicos, 2002. 274p.

GALLAZZI, A. A sociedade perfeita segundo os sadocitas. Revista de Interpretação Bíblica Latino-Americana, Petrópolis \& São Leopoldo, n. 23, p.161175, 1996.

GRAY, G. B. A critical and exegetical commentary on Numbers. 3. ed. Edinburgh: T. Clark Limited, 1956. 489p.

GRENZER, M. Sede em Massa e Meriba (Ex 17,1-7). Revista de Cultura Teológica, São Paulo, n. 33, p.123-134, 2000.

LUISE SCHOTTROFF; SILVIA SCHROER; MARIE-THERES WACKER. Exegese Feminista. Resultados de pesquisas bíblicas a partir da perspectiva de mulheres. São Leopoldo: Editora Sinodal; EST e CEBI, 2008.

NOTH, M. Numbers. Translated by James D. Martin. London: SCM Press, 1968. $258 p$.

RIVKIN, E. The story of Koah's Rebellion: Key to the formation of the Pentateuch. Seminars papers. Atlanta, p. 574-581, 1988

SCHART, A. Mose und Israel im konflikt: eine redactionsgeschichtliche. Freiburg: Universitatsverlag Schweiz Gottingen Vandenhoeck \& Ruprecht, 1990. (Orbis Biblicus et Orientalis, 98).

STAUBLI, T. Die Bücher Levitikus Numeri. Stuttgart: Verlag Katholisches Bibelwerk, 1996. 550p.

VAN DEN BORN, A. (Org.). Dicionário Enciclopédico da Bíblia. 3. ed. Tradução Frederico Stein. Petrópolis: Vozes, 1971.

WENHAM, G. J. Números: Introdução e Comentário. São Paulo: Sociedade Religiosa Edições Vida Nova \& Associação Religiosa Editora Mundo Cristão, 1985. 